\title{
PROJETOS DE VIDA E PROCESSOS \\ DE ENSINO-APRENDIZAGEM: COMPREENSÃO \\ DOS ALUNOS DO ENSINO MÉDIO
}

\author{
TÂNIA ZANELLA \\ MARIA TERESA CERON TREVISOL
}

\begin{abstract}
RESUMO
O Ensino Médio apresenta dilemas e desafios de diferentes naturezas, entre elas: a curricular, a didático-pedagógica, os entraves relacionados à sua finalidade, o perfil dos alunos e seus desejos, o número de matriculados que permanecem ou se evadem dessa etapa de ensino. Esse estudo objetiva analisar a compreensão dos alunos do terceiro ano do ensino médio, no que tange à organização e condução dos processos de ensino e aprendizagem e, em que medida esses processos colaboram para o alcance dos seus projetos de vida. A pesquisa é caracterizada como qualitativa, de caráter exploratório. Como procedimento de coleta de dados utilizou questionário eletrônico com perguntas abertas e fechadas. A amostra foi composta por 18 alunos do terceiro ano do ensino médio, do período noturno. A análise dos dados aconteceu mediante a análise de conteúdo das respostas dos sujeitos pesquisados e, nos permitiu compreender que os alunos percebem os processos de ensino e aprendizagem de maneira positiva, sendo que estes contribuem para o alcance de seus projetos de vida. Identificamos que o caráter propedêutico é predominante na instituição escolar pesquisada e os alunos atribuem ao professor, grande parte da responsabilidade de sua aprendizagem.
\end{abstract}

Palavras-chave: ensino médio; adolescência/juventude; projetos de vida. 


\title{
LIFE PROJECTS AND TEACHING-LEARNING PROCESSES: UNDERSTANDING OF HIGH SCHOOL STUDENTS
}

\begin{abstract}
High school presents dilemmas and challenges of different nature, including: curriculum, the didactic-pedagogic, barriers related to its purpose, the profile of the students and their desires, the number of enrolled staying or evade this educational stage. This study analyzes the understanding of the third year of middle school students as the school organizes and conducts teaching and learning processes, and to what extent these processes work together to achieve their life projects. The research is characterized as qualitative, exploratory. Data collection procedure used electronic questionnaire with open and closed questions. The sample consisted of 18 students of the third year of high school, the nighttime. Data analysis happened upon the content analysis of the responses of the subjects, and allowed us to understand that students perceive the teaching and learning process in a positive way, and these contribute to the achievement of their life projects. We found that the introductory character is predominant in the school institution that was researched, and the students assigned to the teacher, much of the responsibility for their learning.
\end{abstract}

Keywords: high school; teens / youth; project life

\section{INTRODUÇÃO}

O Ensino Médio brasileiro é motivo de preocupações em muitas discussões sobre a educação brasileira. Com o intuito de universalizar essa etapa de ensino para a população brasileira, foi aprovada a Emenda Constitucional no 59/2009, que amplia a obrigatoriedade escolar para a faixa dos 04 anos aos 17 anos. Em 2014, a UNICEF (Fundo das Nações Unidas para a Infância) realizou uma pesquisa no Brasil, que possibilitou ter um panorama da situação do Ensino Médio brasileiro, indicando os dez desafios a serem enfrentados para que se tenha um ensino democrático, universalizado e de qualidade. Nesse estudo foi possível verificar 
que, de acordo com os dados do Resumo Técnico do Censo Escolar da Educação Básica 2012, publicado pelo por extenso na primeira menção (Inep), as matrículas do ensino médio brasileiro estão retraindo-se ao invés de expandir-se. Nos anos de 1996 e 2001 as matrículas dessa etapa de ensino cresceram 47\%, passando de aproximadamente 5,7 milhões para 8,4 milhões; no quinquênio seguinte (2002-2006) aumentaram apenas 2,2\%. A partir de 2007, as matrículas passaram a decrescer e a retração continuou até 2012, atingindo um percentual de 5,9\% em relação a 2006 8.376.852 matrículas em 2012 ante 8.906 .820 em 2006. (UNICEF, 2014). De acordo com os dados da Pesquisa Nacional por Amostra de Domicílios (PNAD), entre 2009 e 2011, constatou-se que 1,7 milhão de adolescentes de 15 a 17 anos estão fora da escola, sendo que 3,1 milhões ainda frequentam o ensino fundamental. Outro dado importante é que 31,1\% dos alunos que cursam o ensino médio (cerca de 2,6 milhões) encontram-se em situação de atraso escolar (UNICEF, 2014).

Apesar dos desafios que o Ensino Médio brasileiro apresenta, ainda é considerado uma entrada para o jovem exercer o seu lugar na sociedade, como nos aponta Sposito (2005), a instituição escolar é ainda uma referência para esta geração, embora seja reconhecido os seus limites e dificuldades.

Nesse sentido, o cenário que o século XXI descortina para o ensino médio é de desafios não apenas curriculares ou de evasão escolar, mas sim, de uma geração de alunos cujos professores, advindos de uma educação tradicional, não estão acostumados e, nem sempre estimulados a recebê-los. Segundo Oliveira e Tomazetti (2010), não podemos mais ignorar as novas linguagens e as novas formas de interação que os alunos adolescentes veiculam no espaço escolar. É peculiar reconhecer que o jovem da sociedade do conhecimento busca processos de subjetivação diferenciados do jovem da sociedade do século XX (ORTEGA, 2006), onde, o contexto social os influencia, descortinando uma nova condição juvenil, que resulta dos processos mais amplos da socialização (LEÃO; DAYRELL; REIS, 2011a).

O jovem busca a sua identidade, uma vez que a adolescência é considerada a última fase da infância rumo à vida adulta 
(ERIKSON, 1976), e esse quer o reconhecimento de quem ele é, de sua afirmação no mundo. A busca constante do "eu", da sua identidade, não é algo inato, mas, sim construído historicamente. $\mathrm{O}$ adolescente procura uma oportunidade de definir-se, de ser reconhecido não mais com a identificação da infância, mas, sim com novas identificações onde pode optar por uma ou outra direção.

Não obstante, o papel que cada adolescente vai desempenhar no contexto social e as responsabilidades que vai assumindo aos poucos, causa, um estranhamento e muitas confusões quanto a encontrar o caminho adequado para sua realização, na ânsia de tornar-se um adulto satisfeito. Esse período é quando os adolescentes fazem as escolhas de vestibulares para suas futuras profissões e encaminham-se para assumir o seu papel social e delineiam seus futuros projetos de vida, ou seja, o adolescente abre-se ao campo das possibilidades de escolhas, aliando seus interesses, habilidades, desejos e expectativas, para construir e poder elaborar um caminho em sua vida. "Tais elaborações dependem sempre de um campo de possibilidades dado pelo contexto socioeconômico e cultural no qual cada jovem se encontra inserido e que circunscreve suas experiências" (LEÃO; DAYRELL; REIS, 2011b, p. 1072). Um projeto de vida não é algo imutável e estático, transformando-se à medida que os próprios jovens vão amadurecendo, são futuros possíveis que se tornam mais consistentes ao tempo que os jovens adquirem seu papel social e sentem-se úteis diante a sociedade.

Saber "lidar" com as transformações da adolescência envolve a todos: pais, professores, profissionais da saúde, sociedade em geral e, muitos dos conflitos relacionais, escolha do que querem seguir para suas vidas, conflitos identitários ficam em evidência no espaço escolar, o que nos remete a repensar qual a função social da escola em tempos de novas tecnologias e mudanças aceleradas.

\section{A FUNÇÃO SOCIAL DA ESCOLA}

A educação ocidental, em seu percurso, é considerada uma evolução. Isto não significa que essa tenha acontecido de maneira pacífica, com consensos generalizados, pois, desde o momento 
em que a sociedade se apercebe de que os ensinamentos aprendidos na instituição familiar e no local de trabalho não são mais suficientes para as funções sociais desempenhadas pelos sujeitos, a escola surge para desempenhar tal função (ENGUITA, 1989). Inicialmente a escola não atendia a fins economicistas, e sim políticos, religiosos e/ou militares; no entanto, com as mudanças do modo de produção e o surgimento do sistema fabril, a educação passa a incorporar cada vez mais os ditames do mercado e, na atualidade, acaba sucumbindo aos organismos internacionais e atendendo à política mercantil. A ação de atender à lógica economicista aconteceu dentro de um processo histórico, cultural, social e político, pois,

...a educação é (...) um processo social que se enquadra numa concepção determinada de mundo, a qual determina os fins a serem atingidos pelo ato educativo, em consonância com as ideias dominantes de uma sociedade. O fenômeno educativo não pode ser, pois, entendido de maneira fragmentada, ou como uma abstração válida para qualquer tempo e lugar, mas sim, como uma prática social, situada historicamente, numa realidade total, que envolve aspectos valorativos, culturais, políticos e econômicos, que permeiam a vida total do homem concreto a que a educação diz respeito (SCHAFRANSKI, 2005, p. 102).

Denota-se que, nesse contexto, o sistema educacional desenvolve-se a partir de paradigmas presentes de um dado momento histórico de determinada sociedade. No século XIX, um dos paradigmas que teve forte influência foi o positivismo, submetendo o conhecimento à sua fragmentação, por entender, que esse deveria ser linear e desenvolver o raciocínio lógico e formal, influenciando a organização dos conhecimentos acadêmicos através dos currículos, demarcados pela forte presença da reprodução de conteúdo, "onde a ênfase se encontra na memorização (...) e no produto do processo pedagógico" (SCHAFRANSKI, 2005, p. 104). 
O aluno é visto, por esse paradigma, como um simples reprodutor do conhecimento, o que é uma visão reducionista que comprometeu as práticas pedagógicas por um longo período. Essas estavam prioritariamente intrincadas com o sistema de poder, trabalhando as disciplinas de forma isolada e envolvidas com os resultados escolares, não importando se o conhecimento transmitido teria alguma contextualização com a realidade do aluno. Émile Dürkheim (1858-1917), sociólogo, foi adepto do paradigma positivista e elaborou sua obra em um contexto social marcado por crises econômicas, depressões e pela primeira guerra mundial. Entendia que a educação era um fenômeno social e, portanto, "uma poderosa ferramenta para a construção gradativa de uma moral coletiva, fundamental para a continuidade capitalista" (LUCENA, 2010, p. 295).

Defendia uma homogeneidade entre os indivíduos para que as sociedades sobrevivessem, afirmando que a educação deveria realizar esse fortalecimento, incutindo nos alunos as semelhanças e características exigidas pela vida coletiva. Dürkheim (2011, p. 53 e 54) define a educação como sendo:

...a ação exercida pelas gerações adultas sobre aquelas que ainda não estão maturas para a vida social. Ela tem como objetivo suscitar e desenvolver na criança um certo número de estados físicos, intelectuais e morais exigidos tanto pelo conjunto da sociedade política quanto pelo meio específico ao qual está destinada em particular.

Destaca-se assim a importância que o autor delegava ao professor no sentido de ser responsável por passar o conhecimento, pois, ele, adulto, teria uma maior bagagem e experiência social para exercer a ação de educar as gerações mais novas, adaptando-as ao meio social no qual estarão destinadas a viver. Outro aspecto importante que o autor apresenta em sua teoria, é a de que existem dois seres em nós - inseparáveis - porém distintos.

Um é composto de todos os estados mentais que dizem respeito apenas a nós mesmos e aos acontecimentos da 
nossa vida pessoal: é o que se poderia chamar de ser individual. O outro é um sistema de ideias, sentimentos e hábitos que exprimem em nós não a nossa personalidade, mas sim o grupo ou os grupos diferentes dos quais fazemos parte; tais como as crenças religiosas, as crenças e práticas morais, as tradições nacionais e profissionais e as opiniões coletivas de todo tipo. Este conjunto forma o ser social. Constituir este ser em cada um de nós é o objetivo da educação (DÜRKHEIM, 2011, p. 54).

Para o autor, aí reside a importância e o papel da educação, uma vez que o ser social não se encontra pronto e acabado, pois, não nascemos com essa constituição espontaneamente. Foi no desenvolvimento da própria sociedade que os indivíduos sentiram a necessidade de venerar deuses e atribuir questões morais ao cotidiano, ou seja, a educação não se limita, a desenvolver o ser individual, "ela cria um novo ser no homem" (DÜRKHEIM, 2011, p. 55). Para o autor, isso aconteceu porque a vida social tornou-se complexa demais para ser entendida sem reflexões. Entretanto, para manter o equilíbrio, o consenso e a harmonia social, "a escola (...) assume para si a tarefa específica de intermediar a coerção que a sociedade exerce sobre o indivíduo buscando alcançar mais rapidamente o processo de socialização. Deste modo, o instrumento básico para evitar a desagregação é a educação" (CARVALHO; CARVALHO, 2000, p. 87).

Nesse sentido, a educação é importante para manter a coesão social, em que os ajustes necessários devem ser realizados para manter a harmonia e o equilíbrio, principalmente nas relações de divisão do trabalho, onde cada parte do organismo social cumpre sua função. Educar as novas gerações com esse intuito foi o motivador da tese de Dürkheim, rememorando que, diante da situação social em que se encontrava na França, essa era a urgência daquela época. A importância dessa teoria para a educação é que o autor faz uma relação da educação com as normas sociais e a cultura, enfatizando o coletivo e não as capacidades individuais, inserindo a escola na sociedade em que se encontra. Durkheim (2011) enfatiza que, em qualquer época 
haverá um tipo de sistema educacional, e que esse será imposto de maneira irresistível, ou seja, a educação como é composta nas diferentes épocas sempre será fruto de uma sociedade emergente e atenderá aos princípios dessa.

Avançando no tempo histórico e voltando-se para a realidade do Brasil, encontramos em Paulo Freire (2007) uma teoria pioneira que evidencia um papel de escola, da educação e dos processos de ensino e de aprendizagem diferenciados, mediatizados pelo diálogo, por um sistema de trocas, em que a educação e os processos de ensino devem oportunizar aos alunos uma perspectiva libertadora e transformadora de si e da sociedade em que estão inseridos. Refuta a ideia de que o professor é quem determina e transmite o que o aluno tem que aprender; para Freire, ninguém ensina ninguém, portanto, o educador e o educando aprendem mutuamente.

Freire (2007) reconhecia que o conhecimento era uma produção social, resultante da ação e reflexão de cada ser humano, dentro do seu contexto histórico e social, pois esse deveria não apenas estar no mundo, mas com ele.

Para Freire, a educação é uma prática libertadora que visa, através da reflexão e da ação, tornar o oprimido independente, pois, "não podemos esquecer que a libertação dos oprimidos é libertação de homens e não de coisas. Por isto, se não é autolibertação - ninguém se liberta sozinho -, também não é libertação de uns feita por outro" (FREIRE, 1987, p. 53). Segundo Maciel (2011, p.338) Paulo Freire reconhecia que "sair da condição de oprimido não é simplesmente deslocar-se para a função de opressor", pois, é primordial que se estabeleçam relações sociais de igualdade, buscando mais que a pseudoparticipação e sim o verdadeiro engajamento. Nessa concepção "educador e educandos (liderança e massas), cointencionados à realidade, se encontram numa tarefa em que ambos são sujeitos no ato, não só de desvelá-la e, assim, criticamente conhecê-la, mas também no de recriar este conhecimento" (FREIRE, 1987, p. 56).

Por serem, educador e educandos, parceiros da construção do conhecimento, é que Freire faz críticas à educação bancária. 
Uma educação que faz dos educandos meros depositários de conteúdo, que são memorizados e guardados, não tendo conexão com a realidade vivenciada pelos educandos, é uma educação baseada em relações fundamentalmente narrativas.

Uma pedagogia que supera a contradição educador-educando, estimulando a mediação pelo diálogo, enquanto o "educador já não é o que apenas educa, mas o que, enquanto educa, é educado, em diálogo com o educando que, ao ser educado, também educa" (FREIRE, 1987, p. 68). Uma relação dialógica, onde ninguém educa ninguém, pois, educa-se em comunhão mediatizados pelo mundo, realizando um constante ato de desvelamento da realidade, na "busca pela emersão das consciências, de que resulte sua inserção crítica" (FREIRE, 1987, p. 70). O diálogo assume posição primordial, pois é o caminho que dá significação aos indivíduos, por estimular um pensar crítico, onde o sujeito desenvolve a comunicação, junto com a interação a fim de construir o seu conhecimento, humanizando-se e desenvolvendo sua formação democrática.

$\mathrm{Na}$ educação libertadora o ponto fundamental para o educador é que esteja ciente que educar não é transferir conhecimento. Freire (1996), faz severas críticas a essa educação, pois, aprender é uma aventura criadora e não determinista, afinal o mundo está sendo e não é. A prática docente deve ser ética, e o educador deve ter amorosidade pelos seus educandos bem como comprometimento com o processo formador.

Podemos inferir que a função social da escola em Freire (2007) passa pela concepção de que pertence ao contexto sócio-histórico, que não existe a neutralidade do sistema educacional e que esse serve a alguma ideologia; suas contribuições vêm firmar uma mediatização entre os educadores e educandos, numa relação onde todos aprendem, em que os conhecimentos dos educandos são valorizados pelos educadores, que não assumem uma postura de apenas repassar os conteúdos. A prática e a teoria andam juntas, numa perspectiva dialógica, política, gnosiológica, em que o educando se humaniza e percebe-se inserido dentro de uma sociedade que pode ser transformada por ele e está em constante transformação. É uma teoria progressista que 
vislumbra o potencial transformador da educação, sob a perspectiva dialética que se estabelece com a sociedade.

Atualmente a dinâmica da sociedade contemporânea, com a globalização e a revolução das tecnologias, juntamente com o desenvolvimento econômico e social, vem impor novas solicitações à educação para atender esse formato social, dentro das exigências do neoliberalismo. A lógica do mercado necessita de pessoas flexíveis, dinâmicas, proativas, competitivas e com capacidade de trabalhar em grupos, sendo que nesse cenário "a educação passa a ser vista, apenas em seu objetivo imediato de servir ao capital, (...) levando as instituições educativas a uma descaracterização de sua função primordial, ou seja, o comprometimento com a formação integral dos indivíduos" (SCHAFRANSKI, 2005, p. 108).

É primordial que a escola discuta esses novos desafios, já que é considerado o melhor investimento social e, como afirmam Pourtois e Desmet (1999), que essa possa contribuir para o ensino e aprendizado dos alunos. Com as novas tecnologias, a escola deixa de ser a detentora do saber, reordenando dessa maneira seu papel dentro da sociedade, pois, "à escola foi delegada a função de formação das novas gerações em termos de acesso à cultura socialmente valorizada, de formação do cidadão e de constituição do sujeito social” (BUENO, 2001, p. 105).

Não basta apenas ter acesso ao conhecimento e à informação que nos chegam de todos os lados; é preciso saber adquiri-la, compreendê-la, interpretá-la, analisá-la e comunicá-la (POZO, 2004). De acordo com Machado (2004, apud REIS, 2014), ter acesso às informações não significa ter acréscimo de conhecimento, pois esse pode tornar-se vazio, sem significação alguma para o sujeito e as relações com o seu mundo.

Nesse sentido o governo, com o intuito de melhorar o ensino médio brasileiro, aprovou o Parecer CNE/CEB $\mathrm{n}^{\circ}$ 5/2011 e a Resolução no 2, de 30 de janeiro de 2012, em que estabelece as Diretrizes Curriculares Nacionais para o Ensino Médio, aplicando-se a todas as formas e modalidades de Ensino Médio, que poderão ser complementadas por diretrizes próprias, se assim se fizer necessário. Segundo Silva e Colontonio (2014), 
as justificativas para que se elaborassem as novas diretrizes curriculares do Ensino Médio, fizeram-se necessárias devido às

...novas exigências educacionais decorrentes da aceleração da produção de conhecimentos, da ampliação do acesso às informações, da criação de novos meios de comunicação, das alterações do mundo do trabalho, e das mudanças de interesse dos adolescentes e jovens, sujeitos dessa etapa educacional (BRASIL, 2011, p.1).

Essa nova organização curricular, de acordo com o parecer, considera as necessidades dos jovens frente à sociedade contemporânea, incorporando as transformações sociais que incitam novos estilos de vida, onde o aprendizado passa pela prerrogativa do acesso ao novo, ao mais atualizado (REIS, 2014).

\section{JUVENTUDE E PROJETOS DE VIDA}

Diante de todas as nuances físicas, psicológicas, sociais e culturais que envolvem a adolescência, a escola assume um papel preponderante nessa fase do desenvolvimento. De acordo com os autores Leão, Dayrell e Reis (2011b, p. 1068), "levar em conta o jovem no aluno implica reconhecer a vivência da juventude, desde a adolescência, tende a ser caracterizada por experimentações em todas as dimensões da vida subjetiva e social." Grande parte dos sujeitos da escola, vê o jovem apenas como aluno e esquece da sua dimensão social, biológica e histórica, corroborando para que "nessa compreensão, pouco se apreende sobre os sujeitos reais que frequentam a escola, as múltiplas dimensões da sua experiência social, suas demandas e expectativas" (LEÃO; DAYRELL; REIS; 2011b, p. 1068).

Atualmente a juventude apresenta características peculiares de uma sociedade pós-moderna, marcada pelo pensamento liberal, pela ânsia de liberdade e elevada importância para o momento presente (SZAPIRO; RESENDE, 2010).

Visto que as transformações ocorridas na sociedade afetam diretamente a maneira que a juventude se configura, é fato que a escola, permeada por relações sociais tão significativas para os 
jovens, corresponde à sua necessidade de firmar sua identidade, e que o "ser aluno adquire uma gradação de importância diferente, indo de uma obrigatoriedade que se deve suportar até a possibilidade de usar a escola como um motor de projeção social posterior" (SILVA; PELISSARI; STEIMBACH; 2013, p. 409).

A escola é invadida pela vida juvenil, com seus looks, pelas grifes, pelo comércio de artigos juvenis, constituindo-se como um espaço também para os amores, as amizades, gostos e distinções de todo tipo. (...) O cotidiano escolar torna-se um espaço complexo de interações, com demarcação de identidades e estilos, visíveis na formação dos mais diferentes grupos, que nem sempre coincidem com aqueles que os jovens formam fora dela. A escola aparece como um espaço aberto a uma vida não-escolar, numa comunidade juvenil de reconhecimento interpessoal. (DAYRELL, 2007, p. 1120)

O jovem leva para a escola, vivências do seu cotidiano, que vão influenciar a sua condição de tornar-se jovem, interferindo nas suas experiências escolares e na importância que esse atribui ao espaço escolar. Vale reiterar que a escola é permeada por diferentes situações de relações sociais, em que o jovem se vê envolvido em conflitos, alianças, imposição de regras, normas e confrontos com todos os sujeitos envolvidos nessa instituição.

Considerando que a juventude é uma fase em que muitas inquietações e inseguranças são vivenciadas, bem como é a fase da afirmação de uma nova identidade, o jovem vê-se diante da pressão de fazer escolhas (profissionais, pessoais, econômicas, familiares e sociais), buscando seu reconhecimento e espaço dentro da sociedade.

Entretanto, se considerarmos a fase da juventude como uma preparação para a vida adulta (ERIKSON, 1976), o presente adquire uma dimensão essencial para o sucesso do futuro. Para Leccardi (2005) o presente não é apenas uma ponte de ligação entre o passado e o futuro, mas sim, a dimensão que o prepara. "Da mesma maneira, o tempo de vida juvenil, graças à relação 
positiva com o presente, construída em torno do devir que ela prefigura, pode ser representado como um tempo de espera ativa, uma fase que deve consentir uma transição por sua vez positiva para a idade adulta" (LECCARDI, 2005, p. 35).

O momento presente perspectiva a projeção do jovem num tempo vindouro, “o futuro é o espaço para a construção de um projeto de vida e, ao mesmo tempo, para a definição de si: projetando que coisa se fará no futuro, projeta-se também, paralelamente, quem se será" (LECCARDI, 2005, p. 36).

Dessa maneira, o jovem necessita encontrar possibilidades que incitem a uma direção, pois, como salienta Ortega y Gasset (1987), viver é caminhar para uma meta, afinal uma vida que caminha sem uma meta, com muita disponibilidade, não tem uma direção e não há expectativas de um porvir.

Mas, afinal como podemos definir o que é um projeto vital ou projeto de vida sincero, que pode dar um significado e direcionamento na vida dos jovens? Para Damon (2009, p. 53) "projeto vital é uma intenção estável e generalizada de alcançar algo que é ao mesmo tempo significativo para o eu e gera consequências no mundo além do eu". Ter um projeto vital leva o indivíduo a ter satisfação pessoal, onde esse se sente integrado em sua sociedade, vislumbrando algo além de uma ambição egóica, pois, implica em querer fazer a diferença não somente para ele, mas para outras pessoas, gerando, então, felicidade, que é "o comprometimento com algo que a pessoa considere envolvente, desafiador e atraente" (DAMON, 2009, p. 49).

O projeto de vida se vincula a um conjunto de características que define o sujeito. Esta definição sedimenta-se no valor e poder que o sujeito atribui a si, aos outros e ao mundo. O projeto de vida estrutura-se em uma dinâmica psicossocial, na medida em que a construção de um projeto tanto possui marcas pessoais ligadas às idiossincrasias na maneira de perceber a si mesmo, os outros e o mundo como marcas da sociabilidade, do viver e aprender com os outros. (NASCIMENTO, 2013, p. 89) 
Portanto, os projetos de vida estão em constante reestruturação, pois, a história de vida do jovem vai redimensionando ou modificando sua maneira de ver a sua realidade, bem como suas expectativas, sonhos e a possibilidade de realizações. Nessas condições é notável que o projeto de vida se articule com a identidade pessoal e social, sendo que o desenvolvimento integral dos projetos de vida, supõe a "interrelação de aspectos físicos, emocionais, intelectuais, sociais e espirituais do indivíduo" (D'ANGELO, 2000, p. 271).

Para Leão, Dayrell e Reis (2011b), o projeto de vida possui uma dinâmica própria e, à medida em que os jovens vão amadurecendo e adquirindo experiências dentro das possibilidades que o mundo proporciona, esse projeto ganha consistência e transforma-se num plano de ação que o jovem se propõe a realizar.

Há que se perguntar, como o currículo escolar, que segundo as políticas educacionais preconizam uma formação para a vida, contribui para os projetos de vida desses jovens que logo terão que fazer escolhas, seja para ingressar num curso superior, trabalhar, iniciar uma família, ou participar de algum projeto social, entre tantas outras possibilidades, considerando que, também, passam por uma fase de desenvolvimento conturbada que é a adolescência, influenciados pelas mudanças imediatistas de um mundo globalizado?

De acordo com Damon (2009), é fundamental que pensemos em oportunizar aos jovens, principalmente na escola, informações sobre como podem idealizar seus projetos vitais, ao passo, que os jovens tenham coragem para formular questões essenciais buscando serem verdadeiros em suas intenções e nas suas escolhas para a vida, pois, caso contrário, correm o risco de termos uma geração que não sabe o que vai querer de seu futuro, ou ainda pior, que reluta em assumir a vida adulta. A escola nessa configuração, segundo o autor, não deixaria de desempenhar as orientações do currículo, mas nesse âmbito, questionar os estudantes de como esse conhecimento acadêmico poderá ser utilizado no mundo fora da escola, ou seja, colocando em pauta o objetivo de aprender e a contribuição do que aprendem para o seu dia a dia. 
A escola, também, promove o encontro da diversidade de modos de vida, culturas e valores, contribuindo para concepções mais amplas e complexas da realidade, o que pode resultar na sensibilidade individual para perceber e envolver-se com problemas ou causas que, muitas vezes, só se tornam visíveis por meio da problematização e discussão (KLEIN, 2011, p. 47 e 48).

Por fim, o jovem de hoje precisa voltar a acreditar que pode e deve fazer a diferença na sociedade, principalmente na sua trajetória de vida. Afinal o projeto de vida está articulado com seus desejos, suas habilidades, seus valores éticos e morais. Enfim, é preciso buscar definir quem ele quer ser e o que quer fazer, a partir das reformulações de suas experiências, pois, talvez, nessa fase de desenvolvimento, a cobrança e a necessidade de olhar-se para o futuro seja de maior intensidade do que em outras etapas do desenvolvimento humano.

\section{METODOLOGIA}

A referida análise é resultado dos dados coletados por meio de um questionário, com perguntas abertas e fechadas, realizados com alunos do $3^{\circ}$ ano do Ensino Médio, da Escola de Educação Básica Maura de Senna Pereira, localizada no Município de Pinheiro Preto, Santa Catarina. Dos 27 (vinte e sete) alunos do $3^{\circ}$ ano, apenas 18 (dezoito) interessaram-se em responder ao questionário, sendo que 9 (nove) alunos não demonstraram interesse, mesmo após enfatizarmos a importância da pesquisa para a área educacional e para os estudantes.

Para coletar os dados dessa pesquisa, inicialmente realizamos um estudo piloto, com 2 (dois) alunos da amostra descrita anteriormente, a fim de verificarmos se haveria compreensão das questões e se a linguagem utilizada era apropriada. Verificamos que os estudantes apresentaram algumas dificuldades nas interpretações dos enunciados das perguntas, o que gerou algumas mudanças nas questões apontadas, adequando a linguagem das mesmas para o melhor entendimento dos sujeitos pesquisados. 
Dos sujeitos que participaram da amostra, predominou o sexo feminino, com 11 (onze) participantes e 7 (sete) do sexo masculino. A faixa etária encontrada foi de: 10 participantes com 17 (dezessete) anos; 5 (cinco) com 16 (dezesseis); 1 (um) com 18 (dezoito) anos; 1 (um) com 19 (dezenove) anos e 1(um) com 15 (quinze) anos. Esse dado demonstra que, embora tenhamos alunos acima da faixa etária da última etapa da Educação Básica, a predominância é de alunos com a faixa etária condizente com o nível dessa etapa de ensino.

Os alunos participantes serão identificados pela letra A (aluno) e número: A1 (aluno 1), A2 (aluno 2), A3 (aluno 3) e, assim, sucessivamente. Por tratar-se de uma pesquisa qualitativa, os dados serão apresentados em forma de gráfico para as perguntas fechadas que apresentam dados quantitativos, sendo que para a interpretação de todos os dados encontrados na pesquisa utilizaremos a análise de conteúdo, pois, segundo Caregnato e Mutti (2006, p. 682) na análise de conteúdo "o texto é um meio de expressão do sujeito, onde o analista busca categorizar as unidades de texto (palavras ou frases) que se repetem, inferindo uma expressão que as representem".

\section{RESULTADOS}

Pensando a escola como a instituição em que os processos de ensino e aprendizagem são oportunizados com o enfoque da formação do aluno, investigamos sob a perspectiva dos alunos, como eles avaliam esse processo na etapa final da Educação Básica, o Ensino Médio. Nesse sentido, os alunos avaliaram a maneira pela qual os professores do Ensino Médio desenvolvem as atividades em sala de aula e se estas estariam colaborando ou não para o processo de ensino e aprendizagem.

Observamos que a maioria dos sujeitos, 67\%, percebe que a maneira como os professores explicam e orientam suas atividades em sala de aula colabora com o processo de aprendizagem. Entre as argumentações mais frequentes que os alunos elencaram, destacam-se: "Por que a aprendizagem vem da explicação das matérias. (A6)"; "por que, com uma boa explicação é melhor de entender o conteúdo. (A8)"; "pois a aprendizagem tem que partir de algum ponto, e os profes- 
sores fazem um grande ponto de partida. (A15)"; "Porque na forma de educadora, seu dever é repassar o conhecimento que não conseguir adquirir sozinho. (A17)"; "Vai relacionar com a faculdade futuramente. (A9)". Evidenciamos que as argumentações dos sujeitos pesquisados estão relacionadas ainda à forma conteudista de aprendizagem, usadas para definir as intenções educacionais. No entanto, Zabala (1998, p. 30), aponta que os conteúdos não deveriam ser pensados unicamente pelas disciplinas tradicionais, pois, "serão conteúdos de aprendizagem todos aqueles que possibilitem o desenvolvimento das capacidades motoras, afetivas, de relação interpessoal e de inserção social", o que determina um currículo integrado, que não vise apenas o enfoque conteudista, como previsto nas Diretrizes Nacionais Curriculares para o Ensino Médio.

No entanto, não se trata de apenas centralizar o aluno no processo de aprendizagem. É preciso que o professor assuma um papel ativo dentro desse processo, incitando no aluno, de forma atrativa e prazerosa, a busca constante pelo conhecimento e pelo desenvolvimento de suas capacidades. Como nos apontam as argumentações dos alunos pesquisados, a prática educativa é de suma importância para que ocorra um processo de ensino e aprendizagem efetivo.

Haja vista, a maneira que o ensino médio está estruturado atualmente quer seja curricular, organizacional, tempo das aulas, práticas educativas, ou seja, considerando que a estrutura influência diretamente nos conhecimentos aprendidos, os alunos pesquisados que trouxeram argumentos positivos em relação à estrutura atual do Ensino Médio, versam sobre a explicação e a aprendizagem do conteúdo, como é perceptível nas suas respostas: "Pois em cada aula você grava o que aprendeu, a cada aula todo mundo tem capacidade para pensar e guardar na cabeça. (A4)"; "Por que ensina mais aquilo que o aluno aprende (A11)"; "Os professores estão fazendo muito bem seu trabalho em suas respectivas matérias. (A17)". Diante das respostas, concordamos com Zabala (1998), ao afirmar que os conteúdos são vistos de uma forma reducionista, servindo ainda para o modelo propedêutico e que conforme o nível de escolarização os conteúdos conceituais ganham ênfase em detrimento dos procedimentais e 
atitudinais. "Desta maneira, a tipologia de conteúdos pode nos servir de instrumento para definir as diferentes posições sobre o papel que deve ter o ensino" (ZABALA, 1998, p. 32).

Nas respostas negativas, verificou-se maior criticidade em relação à estrutura vigente: "mais professores formados (A1)"; "Seria interessante o estudo em tempo integral, além das aulas terem maior duração, pois não há nem tempo de "digerir" um conteúdo que o outro professor entra já falando de outra coisa. (A16)"; "maior tecnologia e maior capacitação dos professores (A15)" e "maior tempo de duração das aulas (A18)". Evidenciamos nessas falas, alguns temas principais, como: formação de professores, ensino em tempo integral, tempo de duração das aulas e tecnologias. Denotamos que as argumentações das respostas negativas, refletem o que há muito no Brasil identifica-se como dilemas a serem resolvidos na organização do sistema educacional. Segundo Mitrulis (2002) com a universalização do ensino médio, há que se impor mudanças significativas da cultura e das práticas escolares, uma vez que essa etapa de ensino é convocada a contribuir para uma formação mais geral e equilibrada. Essa formação deve ser pautada nos valores de inclusão e protagonismo social, a fim de os jovens participarem da modernização e democratização da sociedade, pois, nesse sentido a educação é vista como um elemento de desenvolvimento social.

Especificamente quanto à formação de professores, o documento orientador do Pacto Nacional pelo Ensino Médio (2013) enfatiza que a formação não apresente mais um caráter emergencial e descontínuo, para que os professores tenham uma prática que atenda a demanda dos jovens, juntamente com o desenvolvimento de um currículo orientado pelas Diretrizes Curriculares Nacionais para o Ensino Médio. Kuenzer (2011, p. 672), aponta que "a política de formação só tem sentido quando integrada à estruturação da carreira docente, à política salarial que assegure a dignidade do professor e à garantia de condições adequadas de trabalho".

Quanto aos fatores que comprometem os processos de ensino e aprendizagem, na compreensão dos alunos pesquisados, verificamos que estes, sinalizam a indisciplina como algo que des- 
favorece a efetivação desse processo, sendo esse um dos grandes entraves da educação atualmente, não apenas no Ensino Médio, mas em todas as etapas da educação básica. Observamos ainda que a relação de reciprocidade entre professor-aluno é algo que favorece positivamente o aprendizado, desde que essa relação tenha uma conotação de parceria, a fim de criar possibilidades para que o aprendizado seja efetivo. Outra limitação, identificada pelos alunos, diz respeito ao uso dos recursos disponíveis na escola, pois, nem sempre o professor utiliza esses recursos para trabalhar com os jovens, tornando as aulas cansativas e reduzidas aos conteúdos didáticos. Verificamos ainda, que os alunos pesquisados veem o professor como o ator principal do processo de ensino e aprendizagem, uma vez que atribuem a ele o sucesso ou não do seu processo. No entanto, o aluno deve ser o ator principal de seu aprendizado, realizando dessa forma uma mediação entre educando e educador, pois, conforme Freire (1987, p. 68) "ninguém educa ninguém, ninguém educa a si mesmo, os homens se educam entre si, mediatizados pelo mundo".

Há uma expectativa positiva, por parte dos jovens pesquisados, de que a escola e os processos de ensino e aprendizagem contribuam para o alcance dos projetos de vida dos mesmos. Corrobora esse ponto o fato de que os alunos associam o processo de ensino e aprendizagem com os seus futuros projetos de vida, sendo que a maioria das respostas deu-se em torno da perspectiva do prosseguimento dos estudos. Nesse sentido, podemos inferir, pelos resultados encontrados, que na escola pesquisada há um forte direcionamento propedêutico, pois, há predominância, segundo os alunos, do enfoque conteudista, além de esse parecer ser o projeto com maior probabilidade de realização, a curto prazo, dos jovens pesquisados. Os projetos vitais que assumiram maior enfoque na visão dos alunos pesquisados foram os projetos vitais econômicos, que se relacionam com o sucesso e o poder social, a estabilidade financeira, a valorização do sucesso e do êxito, da autocapacidade e o reconhecimento social. É interessante observar, que os jovens estão buscando aprovação e seu lugar na sociedade, portanto, é perfeitamente aceitável que o enfoque dos mesmos 
seja para projetos que possuam maior visibilidade e primem por resultados imediatos

\section{CONCLUSÃO}

Considerando que a escola é um lugar de encontros e possibilidades e não apenas uma instituição em que o conhecimento é repassado aos alunos, destacamos que os processos de ensino e aprendizagem, que ocorrem continuamente ao longo de nossas vidas, encontram nessa instituição um lugar privilegiado, pois, ao relacionarem-se com o processo cognitivo do sujeito, estes podem compreender melhor o mundo à sua volta, apresentando, dessa maneira condições de fazer escolhas valorativas para sua vida. Identificamos que o ato de ensinar sempre irá requerer uma visão ampliada de mundo, aliada ao planejamento de ações que possibilitem ao aluno ser protagonista de sua aprendizagem. Nesse sentido, o jovem que está no ensino médio, tem perfeitas condições de relacionar as experiências vivenciadas com a aprendizagem oferecida pela escola. Entretanto, é necessário não perder de vista por que se ensina, para que se ensina, em que medida o que se ensina contribui para a construção dos alunos em diferentes dimensões e, uma delas refere-se aos seus projetos de vida, de futuro. Da mesma forma, não é possível deixar de mencionar o papel fundamental da organização dos processos de ensino e de aprendizagem, considerando que essa organização poderá desencadear o interesse do aluno pelo aprender, bem como, mobilizá-lo a participar desse processo. A escola possui um papel ampliado: colaborar com a construção de alunos críticos e mais compromissados com sua vida e com a realidade social.

Essa pesquisa possibilitou vislumbrar que a instituição escolar assume um papel significante para os alunos em relação aos seus projetos de vida, embora sejam reconhecidos os entraves e as dificuldades que apresenta. Portanto, a instituição escolar poderia contribuir com atividades que instiguem os alunos a se descobrirem, ou seja, que incitem os alunos a conhecerem suas habilidades e capacidades, através de atividades inovadoras, que enfoquem o protagonismo dos alunos e que lhes permitam 
reconhecer sentido naquilo que aprendem. Enfatizamos que a presente pesquisa poderá ter continuação posterior, visto que as interpretações dos dados poderão ser aprofundadas, estendendo-se a um número maior de participantes, perspectivando novas realidades e explanações.

\section{REFERÊNCIAS}

BRASIL. Conselho Nacional de Educação. Parecer CNE/CEB n ${ }^{\circ}$ 5/2011. Diretrizes Curriculares Nacionais para o Ensino Médio. Diário Oficial da União, Poder Executivo, Brasília, 2011.

BUENO, J. G. S. Função social da escola e organização do trabalho pedagógico. Educar. Curitiba, n. 17, p. 101-110. 2001. Disponível em: < http://www.educaremrevista.ufpr.br/arquivos 17/silveira bueno.pdf $>$. Acesso em: 20 mar. 2015.

CAREgnATO, C. A.; MUTTI, R. Pesquisa Qualitativa: análise de discurso versus análise de conteúdo. Texto Contexto Enferm. Florianópolis, v.15, n. 4, out-dez, 2006.

CARVALHO, C. H.; CARVALHO, L. B. O positivismo e o pensamento educacional de Durkheim. Educação e Filosofia, v.14, n.27/28, p. 81-88, 2000, jan-jun e jul-dez.

D’ANGELO, O. Proyecto de vida como categoria básica de interpretacion de la identidad individual y social. Revista Cubana de Psicologia, v. 17, n.3, 2000, p. 270-275.

DAMON, W. O que o jovem quer da vida? Como pais e professores podem orientar e motivar os adolescentes. Trad. Jacqueline Valpassos. Summus: São Paulo, 2009.

DAYRELL, J. A escola "faz" as juventudes? Reflexões em torno da socialização juvenil. Educação e Sociedade, v. 28, n. 100, p. 1105-1128, 2007. Disponível em: < http://www.scielo.br/pdf/es/v28n100/a2228100>. Acesso em: 03 ago. 2015.

DÜRKHEIM, E. Educação e Sociologia. Tradução de StephaniaMatousek. Editora Vozes. Rio de Janeiro, 2011. (Coleção Textos Fundantes de Educação).

ENGUITA, M. F. A face oculta da escola: educação e trabalho no capitalismo. Tradução de Tomaz Tadeu da Silva. Porto Alegre: Artes Médicas, 1989. 
ERIKSON, E. Identidade: juventude e crise. Rio de Janeiro: Zahar, 1976.

FREIRE, P. Pedagogia do oprimido. 31 a Edição. Paz e Terra. Rio de Janeiro, 1987.

FREIRE, P. Pedagogia da autonomia: saberes necessários à prática educativa. $30^{a}$ edição. Paz e Terra. São Paulo. 1996. (Coleção Leitura).

FREIRE, P. Política e educação. $8^{a}$ Edição revisada e ampliada. Villa das Letras. Indaiatuba, São Paulo, 2007. (Coleção Dizer a Palavra).

KLEIN, A. M. Projetos de vida e escola: a percepção de estudantes do ensino médio sobre a contribuição das experiências escolares aos seus projetos de vida. Tese de Doutorado. Faculdade de Educação da Universidade de São Paulo, 2011.

KUENZER, A. Z. A formação de professores para o Ensino Médio: velhos problemas, novos desafios. Educação e Sociedade. Campinas, v. 32, n. 116, p. 667-688, jul - set. 2011.

LEÃO, G.; DAYRELL, J. T.; REIS, J. B. Jovens olhares sobre a escola do Ensino Médio. Caderno Cedes. Campinas, v. 32, n.117, p. 1067-1084, out/ dez. 2011a.

LEÃO, G.; DAYRELL, J. T.; REIS, J. B. Juventude, projetos de vida e ensino médio. Educação e Sociedade. Campinas, v.32, n.117, p. 1067-1084, out/dez. $2011 b$.

LECCARDI, C. Por um novo significado do futuro: mudança social, jovens e tempo. Tradução: Norberto Luiz Guarinello. Tempo Social - Revista de Sociologia da USP, v, 17, n.2, p. 35-57, 2005.

LUCENA, C. O Pensamento Educacional de Émile Durkheim. Revista HISTEDBROnline, Campinas, n. 40, p. 295-305, 2010. Disponível em: < http:// www.histedbr.fe.unicamp.br/revista/edicoes/40/art18_40.pdf $>$. Acesso em: 04 mar. 2015.

MACIEL, K. de F. O pensamento de Paulo Freire na trajetória da educação popular. Educação em Perspectiva, v.2, nº 2, jul-dez, p. 326-344. 2011.

MITRULIS, E. Ensaios de inovação no Ensino Médio. Cadernos de Pesquisa, São Paulo, n. 116, p. 217-244, julho, 2002. 
NASCIMENTO, I. P. Educação e projeto de vida de adolescentes do ensino médio. Eccos - Revista Científica. São Paulo, n. 31, p. 83-100, maio/ago, 2013. Disponível em: $<<\underline{\text { http://pepsic.bvsalud.org/scielo.php?script=sci }}$ arttext\&pid $=$ S1413-666X2006000100004 > . Acesso em: 10 out. 2015.

OLIVEIRA, A. M.; TOMAZETTI, E. M. Novos sujeitos no ensino médio? Reflexões acerca da subjetivação juvenil no cenário escolar contemporâneo. Revista Acta ScientiarumEducation. Maringá, v.32, n.1, p. 127-134, jan/jun. 2010. Disponível em: <http://periodicos.uem.br/ojs/index.php/ActaSciEduc/ article/view/10346>. Acesso em: 07 jan. 2015.

ORTEGA, F. Das utopias sociais às utopias corporais: identidades somáticas e marcas corporais. In: ALMEIDA, M. I. M.; EUGENIO, F. (Ed.). Culturas jovens: novos mapas do afeto. Rio de Janeiro: Jorge Zahar, 2006.

ORTEGA Y GASSET, J. A rebelião das massas. Trad. Marylene Pinto Michael. Martins Fontes: São Paulo, 1987.

POURTOIS, J. P.; DESMET, H. A Educação pós-moderna. São Paulo: Loyola, 1999

POZO, J. I. A sociedade da aprendizagem e o desafio de converter informação em conhecimento. Pátio Revista Pedagógica, Ano VIII, n. 31, ago-out, 2004

REIS, R. Aprender na atualidade e tecnologias: implicações para os estudos do ensino médio. Educação \& Realidade. Porto Alegre, v. 39, n. 4, out-dez, 2014. Disponível em: <http://www.ufrgs.br/edu_realidade>. Acesso em: 28 abr. 2015.

SCHAFRANSKI, M. D. A: educação e as transformações da sociedade. In: Publication UEPG: Ciências humanas, Ciências sociais aplicadas, Linguística, Letras e Artes. Ponta Grossa: Editora UEPG, v.13, n.2, p. 101-113, 2005. Disponível em: < http://www.revistas2.uepg.br/index.php/humanas/article/ view/550>. Acesso em: 19 mar. 2015.

SZAPIRO, A. M.; RESENDE, C. M. de A. Juventude: etapa da vida ou estilo de vida? Psicologia e Sociedade, v.22, n.1, p. 43-49, 2010. Disponível em:< http://www.scielo.br/pdf/psoc/v22n1/v22n1a06.pdf>. Acesso em: 16 set. 2015

SILVA, M. R da.; COLONTONIO, E. M. As Diretrizes Curriculares Nacionais para o Ensino Médio e as proposições sobre o trabalho, ciência, tecnologia e cultura: reflexões necessárias. Revista Brasileira de Educação, v.19, n.58, jul-set, 2014. Disponível em: <http://www.scielo.br/pdf/rbedu/v19n58/05. pdf $>$ Acesso em: 11 mai. 2015 
SILVA, M. R da.; PELISSARI, L. B.; STEIMBACH, A. A. Juventude, escola e trabalho: permanência e abandono na educação profissional técnica do ensino médio. Educação e Pesquisa. São Paulo, v. 39, n. 2, p. 403-417, abr/jun, 2013. Disponível em: < http://www.scielo.br/pdf/ep/v39n2/aop899.pdf> Acesso em: 20 ago. 2015

SPOSITO, M. P. Algumas reflexões e muitas indagações sobre as relações entre juventude e escola no Brasil. In: ABRAMO, Helena W.; BRANCO, Pedro P. M. Retratos da juventude brasileira. Análises de uma pesquisa nacional. São Paulo: Instituto Cidadania; Editora Fundação Perseu Abramo. São Paulo: 2005.

UNICEF. Fundo das Nações Unidas para a Infância. 10 desafios do ensino médio no Brasil: para garantir o direito de aprender de adolescentes de 15 a 17 anos. Coord. Mário Volpi, Maria de Salete Silva e Júlia Ribeiro. $1^{\circ}$ ed. Brasília, 2014.

ZABALA, A. A prática educativa: como ensinar. Artmed. Porto Alegre, 1998.

\section{Mini currículo:}

Tânia Zanella: Mestre em Educação pela Universidade do Oeste de Santa Catarina, Pós-graduada em Psicopedagogia Institucional pela Faculdade Estadual de Filosofia, Ciências e Letras de União da Vitória, Formada em Psicologia pela Universidade do Oeste de Santa Catarina, graduanda de Pedagogia pela Universidade do Oeste de Santa Catarina. Atuante na área escolar e social. E-mail: taniazanella@yahoo.com.br

Maria Teresa Ceron Trevisol: Doutora em Psicologia Escolar e do Desenvolvimento Humano pelo Instituto de Psicologia da Universidade de São Paulo - USP. Docente da graduação e do Programa de Pós-graduação em Educação (PPGEd) da Universidade do Oeste de Santa Catarina - Unoesc - Campus de Joaçaba (SC). E-mail: mariateresa.trevisol@unoesc.edu.br 